\title{
LA PLATERÍA BARROCA Y ROCOCÓ EN LA CAMPIÑA SEVILLANA
}

\author{
PIECES OF SILVERWORK MAKE DURING THE BARROC \\ AND ROCOCO PERIODS IN THE "CAMPIÑA SEVILLANA"
}

\author{
Maria Jesús SANZ \\ Universidad de Sevilla, España \\ mjesuss@us.es
}

\begin{abstract}
Hemos intentado presentar una visión de las obras de plata ejecutadas durante los periodos Barroco y Rococó en el norte y nordeste de la provincia de Sevilla, en una zona llamada "Campiña Sevillana". En este trabajo hemos prestado atención especial a las obras más representativas que todavía existen en las principales poblaciones de esta zona, tales como Carmona, Écija, Estepa, Marchena, Morón, Osuna y Utrera.

Palabras clave: Barroco, Rococó, obras de platería, Campiña Sevillana
\end{abstract}

We try to present a sigh over the silverwork pieces make in the Barroc and Rococo style in the north and northeast of the province of Seville, named "Campiña Sevillana". In that paper we pay special attention to the main works that yet remain in the main cities of this area, so that Carmona, Écija, Estepa, Marchena, Morón, Osuna y Utrera.

Keywords: Barroc, Rococo, silverwork pieces, "Campiña Sevillana"

La nómina de las poblaciones que componen la llamada Campiña Sevillana es muy extensa, si nos ajustamos a las divisiones provinciales, de tal manera que se cuentan dieciocho urbes, pero en realidad no todas ellas contienen las mismas tendencias artísticas que se dan dentro del Barroco, ya que al ser un territorio muy extenso las influencias que les han llegado no son exactamente las mismas.

Por otra parte hay poblaciones pequeñas que no han tenido el desarrollo oportuno para contar con grandes obras de plata labrada, aunque la mayoría son urbes que en los siglos XVII y XVIII tuvieron un importante desarrollo comercial, basado en general en la agricultura. Otras poblaciones de gran desarrollo se hallan tan cerca de la capital que casi todas las influencias recibidas procedían de Sevilla. Sin embargo, en núcleos de importancia, más alejados del centro urbano y ubicados en la gran llanura que se extiende al norte y este de la provincia 
de Sevilla, llamada la Campiña, hubo un gran desarrollo de la platería barroca y rococó.

Los siglos XVII y XVIII suponen un enorme auge en el arte de labrar la plata en toda Andalucía, en la que destacaron las dos principales escuelas, Córdoba y Sevilla. Otras escuelas de relieve fueron las de Granada, Málaga y en la última etapa del Barroco, es decir durante el siglo XVIII, Cádiz. Con respecto a las otras provincias, hay que decir que Jaén, al hallarse en la encrucijada con Castilla La Mancha, participa de otras influencias, además de las del resto de Andalucía. En lo que concierne a Huelva y Almería, hay que señalar que estuvieron hasta el siglo XIX bajo el influjo de Sevilla y Granada, respectivamente.

Las dos principales escuelas ya mencionadas, Córdoba y Sevilla, contaban ya con una tradición renacentista, que había producido grandes obras a lo largo de todo el siglo XVI, y la proximidad de las dos provincias hizo que sus escuelas influyeran en las zonas limítrofes, es decir, en el sur de la provincia de Córdoba, y en el nordeste y este de la provincia de Sevilla, parte importante de la ya mencionada Campiña Sevillana.

Durante la segunda mitad del siglo XVII y todo el XVIII, que significan el desarrollo del estilo Barroco y su fase final, el Rococó, se producen en la ciudad de Sevilla, y en la mencionada área, unos conjuntos de lo más suntuoso, así como numerosas piezas destinadas al culto de los grandes templos que ocupan las ciudades de mayor población en esta área, tales como Carmona, Écija, Estepa, Marchena, Morón, Osuna o Utrera, por citar los principales núcleos donde se hallan estas dobles influencias. Otros centros importantes en la actualidad, como Alcalá de Guadaíra o Dos Hermanas, al estar más cerca de Sevilla, recibieron preferentemente la influencia de la capital sevillana, y de hecho muchos plateros sevillanos residentes en este núcleo urbano, hicieron obras para estas localidades, aunque también trabajaron en centros más lejanos.

La división que hemos hecho no es más que aproximada, y con ello no queremos decir que en ambas ciudades, Córdoba y Sevilla, no se hayan producido obras de interés y calidad antes de estas fechas, pues en ambas ciudades se conservan magníficas obras de los siglos XVI y XVII, e incluso de las etapas inmediatamente anteriores, pero va a ser precisamente durante el desarrollo de los estilos Barroco y Rococó cuando se producirá el gran auge de la plata labrada en esta zona, además de conservarse muchas más piezas.

Ya hemos mencionado cómo durante el período previo, es decir, durante el siglo XVI y la primera mitad del XVII, tanto en Sevilla como en Córdoba el arte de la platería va a tener un gran desarrollo, y entre estos dos polos va a oscilar la platería de la Campiña, es decir, como ya hemos visto, las áreas este y nordeste de la provincia de Sevilla, que limitan con la provincia de Córdoba. Tanto es así que encontraremos piezas marcadas en las dos ciudades, Córdoba y Sevilla, pertenecientes a las iglesias y conventos de las principales poblaciones que hemos 
elegido. Por lo tanto, estas ciudades van a contar con un importante ajuar previo a la formación de sus propias escuelas durante el Barroco y el Rococó.

El hecho de que estas urbes de la Campiña, antes del siglo XVIII, dependiesen de Sevilla se debe a varios factores, siendo los fundamentales, el que formasen parte del Reino de Sevilla, y el que no tuviesen gremio de plateros reconocido antes del siglo XVIII, ni marca propia. Los plateros que querían ejercer como tales en la Campiña tenían que examinarse en Sevilla, y obtener allí su permiso para abrir tienda. Así, muchos de ellos son sevillanos que se establecen en estos lugares, y otros son locales que han recibido su formación en la capital del Reino de Sevilla, para luego establecerse en su ciudad, por lo que no podemos hablar de una gran diferenciación de estilos.

En cuanto a la influencia cordobesa, el principal factor es evidente, la cercanía, y el segundo es la especial situación de los plateros cordobeses para vender su mercancía en cualquier lugar, sin ningún impedimento por parte de sus autoridades, privilegio éste que no se daba en las otras capitales andaluzas.

Tanto la ciudad de Sevilla como la de Córdoba tuvieron gremio de plateros ya desde el Medievo, con obligación de marcar las piezas, que en ambas ciudades se produjeran, conociéndose sus marcas de localidad desde fines del siglo XV, aunque la obligación de marcar las obras de plata es bastante anterior. En la ciudad de Sevilla la obligación de marcar la plata data al menos de 1374, fecha en la que las ordenanzas del gremio ya mencionan esta condición ${ }^{1}$. Para las poblaciones de la Campiña, la constitución de un gremio como tal tardó mucho más en tener lugar, e incluso en algunos sitios nunca llegó a haber un gremio constituido. En el caso de la ciudad de Osuna, su condición de dependencia de los duques debió influir en que nunca llegase a existir una asociación gremial propiamente dicha, aunque recientes investigaciones parecen demostrar la existencia de una marca de Osuna. Con respecto a la ciudad de Carmona, está documentado que, al menos desde 1715, los plateros estaban obligados a marcar la plata, pero hasta el momento no se ha hallado ninguna marca ${ }^{2}$. De Écija se han conservado bastantes marcas, algunas del siglo XVII, y la mayoría del siglo $\mathrm{XVIII}^{3}$, mientras que de otras localidades no se tienen noticias de la existencia de un gremio de plateros, $\mathrm{y}$ en los tres casos mencionados los gremios se formaron muy tardíamente, debido a las normativas del gobierno central.

Otro factor que hay que tener en cuenta para el conocimiento de la platería en estos centros es si existen estudios sobre la materia. En la actualidad sólo

${ }^{1}$ SANZ, María Jesús: El gremio de plateros sevillano. 1344-1867, Sevilla, 1991, pp. 186- 187.

${ }^{2}$ MEJÍAS ÁlVAREZ, María Jesús: Orfebrería religiosa en Carmona. Siglos XV-XIX, Carmona, 2001, p. 33

${ }^{3}$ GARCÍA LEÓN, Gerardo: El arte de la platería en Écija. Siglos $X V$ - XIX, Sevilla, 2001, pp. 225-268, "Platería barroca ecijana", Écija Barroca, Écija, 2011, p.218. 
Carmona y Écija lo tienen de manera específica. Sobre Marchena hay un estudio general sobre el patrimonio de la ciudad, y aunque se hicieron algunos trabajos sobre la platería de sus iglesias y especialmente sobre la de la parroquia de San Juan, sin embargo nunca llegaron a publicarse. Sobre Osuna hay algunas investigaciones parciales, y para las demás poblaciones hay que recurrir a los distintos estudios generales sobre la provincia de Sevilla, tales como catálogos, inventarios y guías ${ }^{4}$.

Otra característica de los conjuntos de plata labrada es la existencia de algunas piezas procedentes de otros lugares, pues aunque la mayoría pertenecen a las escuelas cordobesa y sevillana, existen piezas de lugares mucho más lejanos, tanto españolas como extranjeras, y ello se debe principalmente, en lo que se refiere a la ciudad de Osuna, a la tutela de los duques para con la ciudad, que de hecho les perteneció prácticamente hasta el siglo XIX. Los duques, que eran una de las familias más poderosas de España, tenían palacios en distintos lugares, donde habitaban alternativamente, y además ocuparon cargos importantes fuera de España. Recordemos a los Duques de Osuna, como Virreyes de Nápoles, o embajadores en Venecia, y por ello tenían tratos con orfebres de distintos lugares, a los que les encargaban obras.

Por otra parte, hay que tener en cuenta la plata labrada que venía de América durante la colonización española, que llegaba en su mayoría en forma de objetos de culto, mandados por los indianos a su localidad de origen. En este sentido, hay que decir que durante los siglos XVII y sobre todo XVIII llegaron piezas a casi todas las poblaciones de Andalucía occidental, y que hoy día se conservan, muchas de ellas, en sus templos. Con respecto a las piezas de platería americana existentes en la Campiña, hay que decir que no son tan abundantes como en la provincia de Huelva, en la de Cádiz y en la propia ciudad de Sevilla, pero hay

${ }^{4}$ HERNÁNDEZ DÍAZ, José, SANCHO CORBACHO, Antonio y COLLANTES DE TERÁN, Francisco: Catálogo Arqueológico y artístico de la provincia de Sevilla, tomos II, III y IV, Sevilla, 1943, 1951 y 1955, Sanz, M.J.: Orfebrería sevillana del Barroco, 2 tomos, Sevilla, 1976; Catálogo de orfebrería de la Colegiata de Osuna, Sevilla, 1979; "La orfebrería en el monasterio de la Encarnación de Osuna", Archivo Hispalense, n 190, Sevilla, 1980, pp.105-116, MORALES, Alfredo, SANZ, María Jesús, SERRERA, Juan Miguel y VALDIVIESO, Enrique: Guia artística de Sevilla y su provincia, Sevilla, 1981, $2^{a}$ edic. 2004, MORALES, Alfredo, OLIVER, Alberto, PLEGUEZUELO, Alfonso, SANZ, María Jesús, SERRERA, Juan Miguel y VALDIVIESO, Enrique: Inventario artístico de Sevilla y su provincia, tomos I y II, Madrid, 1982, RAVÉ PRIETO, José Luis: Arte religioso en Marchena, Marchena, 1986, MEJÍAS ÁLVAREZ, María Jesús: Orfebrería religiosa..., op. cit., GARCÍA LEÓN, G.: Ops. cits., A.A.V.V.: Écija Barroca, Écija, 2011, A.A.V.V.: El fulgor de la plata, Andalucía Barroca, Córdoba, 2007. SANTOS MÁRQUEZ, Antonio J.: "Una aproximación al arte de la platería en Osuna", en Estudios de Platería, San Eloy 2003. Murcia, 2003, pp. 553-567. 
bastantes ejemplares en muchas de sus poblaciones, aunque se han perdido muchas obras que se hallan documentadas.

En lo que se refiere a las obras realizadas en Andalucía, la mayoría de las piezas conservadas son de tipo religioso, por lo que residen en las iglesias y conventos. El hecho de la abundancia de obras religiosas, y por el contrario la escasez de las civiles, se debe a que los objetos de culto pertenecían a una comunidad y no se podían vender o deshacer fácilmente, como ocurría en las piezas civiles, ya que, al morir su propietario, los herederos se repartían sus bienes y podían disponer de ellos como quisieran. En el caso de los objetos de plata, podían venderlos o fundirlos, o bien, si los conservaban, al cabo de varias generaciones resultaba imposible seguirles la pista. Únicamente aquellas obras que pertenecían a un organismo civil, como los ayuntamientos, u otras asociaciones de tipo laico, se han conservado en algunos casos, como por ejemplo las mazas, emblemas de poder de los ayuntamientos, y de otros organismos, como las universidades y otras asociaciones de importancia.

En cuanto a la platería religiosa, la variedad de los objetos es muy grande, pues una parte importante de ellos está dedicada al culto directo en contacto con las especies sagradas, como cálices, custodias, copones, portaviáticos, etc., mientras que otro tipo de objetos son auxiliares del culto, como las cruces de altar, las bandejas, las campanillas, los acetres, los atriles o las vinajeras.

Además de estos objetos, hay que mencionar los realizados para el exorno de las imágenes, que en este período del Barroco son muy abundantes y suntuosos. Así, las coronas de la Virgen, las ráfagas o la media luna, son piezas quizá las más lujosas de todas las épocas. En lo que se refiere a la imagen de Jesús, destacan las potencias, y en el caso de los Nazarenos el cíngulo, que en determinados casos puede ser de filigrana de plata, y rara vez de oro. Pero además las cruces de los Nazarenos, especialmente durante el Barroco, se recubren o incrustan con materiales ricos como la plata, el carey, la nácar y el marfil, materiales con los se componen piezas muy impactantes. A todos estos aditamentos de plata, en las imágenes de Cristo y de la Virgen, hay que añadir los de los santos y santas de especial devoción, a los que se les colocaban diademas, coronas y símbolos de su santidad, generalmente de plata.

Situados ya en el panorama de la platería barroca de la Campiña, con su centro entre Sevilla y Córdoba, podemos iniciar el estudio estilístico de los períodos que vamos a tratar, el Barroco y el Rococó, desarrollados desde mediados del siglo XVII hasta finales del siglo XVIII.

Las primeras piezas fechadas de las que disponemos correspondientes al estilo barroco, son dos portapaces y dos bandejas de la parroquia de San Lorenzo de Sevilla (fig.1), procedentes de la misma donación, fechadas las bandejas en 
$1655^{5}$. En ellas aparece ya la típica decoración de hojas y flores carnosas, aunque la estructura de los portapaces es aún muy manierista. En la misma línea, aunque quizás un poco más tardía se encuentra la gran bandeja de la parroquia de Santa Cruz de Écija, que no muestra ninguna marca ni fecha, y según su ornamentación de pequeños insectos introducidos entre los grandes temas geométricos manieristas, no habituales en las obras españolas, se ha aventurado la hipótesis de que podría provenir del sur de Italia, ya que en Palermo existe una muy parecida ${ }^{6}$. La bandeja tiene el escudo de la parroquia de Santa Cruz en el centro, además de unas cartelas con inscripciones en el borde, que fueron añadidas cuando la obra entró en la parroquia en 1709 (figura1b).

El portapaz es pieza de gran interés, pues se halla muy ligado a los estilos arquitectónicos, a los que sigue fielmente, tratando de imitar a un retablo ya desde el siglo XV, y a lo largo de los siglos XVI y XVII va siguiendo los estilos arquitectónicas de cada etapa. Pero será en el último tercio del siglo XVII cuando el pleno estilo barroco se afianzará totalmente en el arte de la platería, y ya podremos contar con obras arquitectónicamente barrocas. Más adelante, durante el último tercio del siglo XVIII, el portapaz rococó se desligará completamente de la estructura del retablo para convertirse en una simple placa decorativa.

No podemos iniciar el estudio de la platería barroca andaluza sin mencionar a la gran figura del Barroco sevillano, Juan Laureano de Pina, nacido en Jerez de la Frontera, pero afincado en Sevilla hasta su muerte, ocurrida en 1723. Éste ha dejando espléndidas muestras de su arte no sólo en su ciudad natal, sino también en Sevilla, donde pasó la mayor parte de su vida, y desde ésta, su ciudad de adopción, su arte se extendió a otras localidades de la provincia, y del Reino de Sevilla, pero también se hallan obras suyas en otras ciudades españolas, e incluso fuera del país, como las piezas que regaló a Tierra Santa.

En 1691 regaló a Tierra Santa un pequeño cuadrito, con una pintura de la Virgen con el Niño, cuyo marco de madera está adornado con temas vegetales de plata. En la parte inferior va una cartela con la inscripción, en latín, del donante y la fecha. Pero su regalo más preciado, en 1695, fue un sagrario a la iglesia del Santo Sepulcro de Jerusalén, que se utiliza el Jueves Santo para poner encima del Sepulcro. Finalmente, al santuario de Aim Karen, situado a 8 kilómetros de Jerusalén y que se considera como la patria de San Juan Bautista, regaló un portapaz, fechado en 1699. Estas dos últimas piezas, el portapaz y el tabernáculo, están bellamente decoradas con los temas vegetales propios del estilo barroco ${ }^{7}$. No obstante, tanto en el portapaz como en el sagrario, los aspectos arquitectónicos no están tan resaltados como en otras obras, pues el portapaz se muestra como una

${ }^{5}$ SANZ, María Jesús: Orfebrería sevillana .., op. cit., t. I, p. 386, fig. 104, t. II p. 233.

${ }^{6}$ GARCÍA LEÓN, Gerardo: "Platería barroca ecijana", op. cit., pp. 300, fig. 54.

${ }^{7}$ SANZ, María Jesús: Juan Laureano de Pina, Sevilla, 1980, pp. 61-64, 109,110, 129131 y $165-171$. 
sencilla placa decorativa cubierta de abundante ornamentación floral, y el sagrario, que es de planta poligonal y cubierta troncopiramidal sigue la misma línea, decorándose con elementos vegetales, relieves y esculturas en el remate, pero sin mostrar ningún elemento arquitectónico.

Su tarea más relevante es la que llevó a cabo en el altar de plata para la catedral de Sevilla ${ }^{8}$, y en la Capilla Real del mismo templo, en la que realizó la urna sepulcral de San Fernando ${ }^{9}$, además de frontales de altar y lámparas. De estas últimas piezas, realizadas para la catedral, han quedado varios ejemplares, algunas de las llamadas lámparas de plato, las más repetidas durante el Barroco, mientras que de las lámparas de brazos, llamadas en esta época «de araña», no han quedado excesivas muestras. De este último modelo se conservan varias en la capilla de la Antigua de la catedral de Sevilla, una de ellas fechada en 1672, aunque se ignora su autor.

Con respecto a las obras de Juan Laureano en la Campiña, destaca el sagrario de la iglesia de San Miguel de Morón, salvado de la quema que sufrió esta iglesia durante la Guerra Civil, en la que desapareció una gran custodia de torre de estilo rococó, que ardió en el rellano de entrada a la iglesia. El sagrario tuvo más suerte, pues al estar incrustado en el retablo, no pudo ser arrancado. La pieza puede decirse que es la más suntuosa de todos los tabernáculos barrocos andaluces, no sólo por sus grandes dimensiones, sino también por su concepto arquitectónico en el que no falta la cúpula aristada, ni las columnas salomónicas, además de mostrar una delicada ornamentación barroca de flores carnosas, que cubren toda la superficie (figura 2). Se fecha en $1686^{10}$.

La introducción de la columna salomónica se hace evidente en las piezas relacionadas con la arquitectura, y especialmente con el retablo, como ya hemos visto en esta última obra mencionada. Como derivación o imitación del retablo, los portapaces se convertirán en pequeños retablitos. Así lo podemos ver en el portapaz de San Miguel de Morón, en el que ya apreciamos el encuadre de la figura de San Miguel entre dos columnas salomónicas. Varios posee la ciudad de Carmona, como los pertenecientes a las parroquias de Santa María, San Bartolomé y San Pedro, cuyo lugar preferente ocupa el santo titular. En todos ellos se reproduce un retablo barroco en miniatura, en el que aparecen columnas, calles, frontón y banco.

La producción de piezas barrocas en Andalucía es enorme, como se puso de manifiesto en la muestra de los años 2007-2008 ${ }^{11}$. No obstante, muchas obras han desaparecido en las guerras, exclaustraciones e invasiones, como la de los

${ }^{8}$ SANZ, María Jesús: "El altar de plata de la catedral de Sevilla", Archivos de la Iglesia de Sevilla. Homenaje al archivero Don Pedro Rubio Merino, Sevilla, 2006, pp.623-640.

${ }^{9}$ SANZ, María Jesús: Juan Laureano..., op. cit., pp. 65-95, láms. 6, 7 y 8.

${ }^{10}$ SANZ, María Jesús:.: "El altar de plata...", op. cit., pp. 57-59 y 157-159.

${ }^{11}$ El fulgor de la plata. Andalucía Barroca, Córdoba, 2007-2008. 
franceses en 1810, las exclaustraciones de 1835-37, las actuaciones del gobierno liberal en 1868-69, y finalmente la Guerra Civil de 1936. En esta última desaparecieron algunas importantes obras, tanto en la provincia de Sevilla, como en la periferia de la ciudad, como por ejemplo la custodia de torre de la parroquia de San Miguel de Morón, ya mencionada. Era una pieza importante de estilo rococó, que medía más de tres metros de altura, y de la que se conoce la fecha y el autor, además de conservarse fotografías.

Algunas poblaciones de la Campiña, así como el centro de la ciudad de Sevilla no sufrieron destrozos en el patrimonio, y por ello se conservan bastantes piezas, en el campo de la orfebrería, como para poder apreciar en ellas el claro estilo barroco, tanto en la expresión de las figuras, como la que muestran los bustos de San Pío y San Laureano, de la catedral de Sevilla, como en las esculturas de cuerpo entero de San Isidoro y San Leandro, del mismo templo. Asimismo, se conserva el gran retablo de plata, para el que se hicieron las mencionadas esculturas, que se puede considerar el más suntuoso de todos los retablos barrocos de plata $^{12}$.

Esta afición por ensalzar el culto a la Eucaristía en las festividades, especialmente dedicadas a ella, hizo que, otras poblaciones también tuvieran retablos de plata, como es el caso del de la parroquia de San Miguel de Morón, que fue destruido durante la Guerra Civil, y sólo queda de él una escultura de San Isidoro.

A pesar de todas las destrucciones de las guerras mencionadas, las obras vinculadas al culto eucarístico son abundantísimas, especialmente durante el Barroco, y van desde los sagrarios y las arcas eucarísticas, hasta los portaviáticos, pasando naturalmente por las custodias, tanto de mano como de asiento, sin dejar por supuesto cálices y copones.

La ciudad de Carmona, posee dos custodias de torre, una del siglo XVI, correspondiente a la parroquia de Santa María, obra de Francisco de Alfaro, que la realizó entre 1579 y $1584^{13}$ y la otra de la primera mitad del siglo XVIII, perteneciente a la de San Pedro. Esta última custodia no puede considerase como una obra propiamente barroca ya que sigue el modelo de la del siglo XVI, y por lo tanto no parece conveniente incluirla dentro del estilo barroco ${ }^{14}$.

Otras muchas piezas de estilo barroco posee la ciudad, con una gran riqueza de obras de platería religiosa, entre las que podrían mencionarse cálices, copones, y otros objetos de culto, como los portapaces antes mencionados. Las obras se

${ }^{12}$ SANZ, María Jesús: "El altar de plata...”, op. cit. pp. 57-59 y 157-159.

13 MEJÍAS ÁlVAREZ, María Jesús: Orfebrería religiosa..., op. cit, pp. 225-229, SANZ, María Jesús y SANTOS MÁRQUEZ, Antonio J.: Francisco de Alfaro y la renovación de la platería sevillana en la segunda mitad del siglo XVI, Sevilla, 2013, pp.103-104.

${ }^{14}$ MEJÍAS ÁLVAREZ, María Jesús: Orfebrería religiosa ..., op. cit, pp. 330-333, y "La custodia procesional de San Pedro de Carmona. Una obra del siglo XVIII", Laboratorio de Arte, nº4, 1991, pp. 169-180. 
hallan repartidas en sus diferentes templos y conventos. Esta riqueza en obras de plata se debió a que Carmona fue un centro importante en la agricultura y en el comercio desde el siglo XVI hasta el XVIII.

Con respecto al marcaje en esta ciudad hay que decir que, en las obras conocidas, hay marcas de distintas ciudades españolas e incluso americanas, pero también las hay de la propia ciudad de Carmona, así como de plateros de esta localidad, pero la marca de la ciudad no aparecerá hasta después de $1715^{15}$. No obstante, como ya anteriormente advertimos, esta población es de las que contienen uno de los mejores conjuntos de platería barroca de la zona de la Campiña.

También Marchena posee importantes obras de platería de varias épocas, como la custodia de la parroquia de San Juan, obra de Francisco de Alfaro realizada entre 1575 y $1580^{16}$. Para determinadas festividades, la custodia se convertía en sagrario, y para ello Juan Laureano de Pina, hacia 1700, le hizo unos paneles que cerraban los vanos del primer cuerpo en los que colocó, junto a los símbolos eucarísticos sostenidos por ángeles, cartelas con textos relativos a la Eucaristía ${ }^{17}$ (figura 3).

Para este fin de guardar las sagradas especies estaban también las urnas eucarísticas, de menor tamaño que las custodias, que solían usarse para poner el Santísimo en las festividades especiales como la de la Semana Santa. Una de las más ricas es la de la parroquia de San Miguel de Marchena (figura 3b), de base poligonal, cuerpo apiramidado y cubierta cupuliforme. Toda la pieza se halla completamente cubierta de ornamentación vegetal muy abultada y dividida en espacios verticales, por lo que recuerda los temas decorativos mexicanos, aunque no hay ninguna referencia que la ubique en los talleres ultramarinos. Podría fecharse en las primeras décadas de la segunda mitad del siglo XVII.

Habíamos visto que la gran figura del barroco andaluz era Juan Laureano de Pina, así como el desarrollo de su trabajo, inicialmente en Jerez de la Frontera, y luego en Sevilla y su provincia, y más tarde incluso fuera de España. Pues bien, desde mediados del siglo XVIII, hay que contar con la gran figura de Damián de Castro, cordobés, nacido en 1716 y muerto en 1793. La mayoría de sus obras fueron realizadas a partir de mediados del siglo, por lo que su estilo se trasformó del último barroco al pleno rococó. Su obra se halla difundida por toda España, e incluso existen piezas en museos extranjeros, dado que la producción de su taller fue extraordinaria.

${ }^{15}$ MEJÍAS ÁLVAREZ, María Jesús: Orfebrería religiosa..., op. cit., pp. 401-438.

${ }^{16}$ RAVÉ PRIETO, José Luis: Arte religioso en Marchena. Siglos XV al XIX, Marchena, 1986, págs. 29-37, SANZ, María Jesús y SANTOS MÁRQUEZ, Antonio J.: Francisco de Alfaro..., op.cit., pp. 101-103 y 111-114.

${ }^{17}$ CRUZ, José Manuel: Cinco siglos de platería sevillana, Sevilla, 1992, p. 242. 
Aunque su lugar de residencia fue Córdoba, en 1758 estuvo en Madrid, pero volvió a Córdoba, para finalmente morir en Sevilla y ser enterrado en la capilla de Los Cálices de la catedral de Sevilla ${ }^{18}$.

Uno de los centros donde su obra fue más difundida, aparte de Córdoba y su provincia, fue Sevilla y su provincia, sobre todo Écija, llegando sus obras también a varios lugares de España como Extremadura, Canarias, Guadalajara y otras poblaciones de la Península Ibérica ${ }^{19}$, además de su exportación de obras al extranjero. Para la catedral de Sigüenza, en la provincia de Guadalajara, realizó una custodia entre 1774 y 1779, perdida durante la Invasión Francesa.

En Écija existen muchas piezas suyas documentadas, todas dedicadas al culto, como por ejemplo el arca sacramental del convento de Santo Domingo, fechada en 1750. El arca presenta varios relieves de simbolismo eucarístico tales como el pelícano con sus crías, y se enmarca en un círculo de nubes del que surgen rayos, presentando un impactante aspecto.

En este sentido hay que decir que no sólo se difundieron las obras de su mano, sino que también hubo muchos plateros que siguieron su estilo, especialmente en Sevilla y su área. Obras como la urna eucarística de San Mateo de Montánchez (Cáceres), en forma de caja de movidos perfiles, coronada por las tres cruces del Calvario, y con la imagen del pelícano entre las grandes rocallas del frente parece estar inspirada en las obras de Castro. La pieza es obra de un platero sevillano llamado José de Alexandre Ezquerra, que la realizó hacia 1775, siguiendo el estilo del cordobés. En la misma línea está el sagrario en forma de caja rococó, con pelícano incluido, del convento de la Encarnación de Osuna, que bien podría ser de Castro o de uno de sus seguidores.

Unas piezas donde mostró la originalidad de su diseño fueron las dos bandejas que hizo para el arzobispo de Sevilla Don Javier Delgado y Venegas en 1777, que iban destinadas a la capilla de la Antigua de la catedral de Sevilla (figura 4). La originalidad consistió en trazar unas aristas ondulantes que, partiendo del medallón central terminaban en los bordes, imprimiendo a la superficie una sensación de movimiento. Algunas décadas más tarde, hacia 1790, fueron imitadas por el platero sevillano Vicente Gargallo. Ambos conjuntos se pueden contemplar hoy en el tesoro de la catedral de Sevilla ${ }^{20}$. Sin embargo, su original modelo de aristas helicoidales no tuvo éxito fuera de este ámbito, pues encontramos otras piezas coetáneas, decoradas con rocalla, pero sin relación alguna con las obras

${ }^{18}$ CRUZ, José Manuel: "Damián de Castro la platería cordobesa en la segunda mitad del siglo XVIII”, El fulgor de la plata, Andalucía barroca, Córdoba, 2007-2008, pp. 112-115.

${ }^{19}$ GARCÍA LEÓN, Gerardo: Le arte de la platería..., op. cit., pp. 229-249.

${ }^{20}$ SANZ, María Jesús: "Vicisitudes del ajuar de plata de la capilla de la Antigua de la catedral de Sevilla", Laboratorio de Arte, n 22, 2010, pp.185-215. 
de Castro, como por ejemplo la bandeja de la parroquia de San Sebastián de Estepa (figura 4b).

En lo que concierne a sus obras fuera de España, hay que citar dos bandejas en la catedral de Caracas con su marca y la del contraste cordobés Taramas ${ }^{21}$, que presentan un diseño diferente. La ornamentación de estas piezas se compone de un botón central elevado rodeado de amplias hojas, ocupando el resto de la superficie una decoración relativamente menuda en la que se adivinan unas pequeñas rocallas. Se las sitúa hacia 1744, con lo cual, si se acepta esa fecha, sería una de las primeras obras en las que aparece la rocalla.

Otro de los objetos relacionados con la devoción a la Eucaristía, muy abundantes en este período, son los portaviáticos, utilizados para llevarla a los enfermos, o bien las cajas eucarísticas utilizadas durante los cultos, que ahora toman las más variadas formas, desde el pelícano, hasta la caja en forma de corazón, o circular. Pero además del pelícano aparecen en estas piezas otros símbolos eucarísticos, como el Cordero sobre el libro, el cáliz, la custodia, o la Última Cena. Tal es el caso del portaviático perteneciente a la parroquia de Santa María de Écija, del último cuarto del siglo XVIII, y el del convento de la Trinidad, de la misma población, algo anterior. Los de forma de pelícano son también muy tardíos, casi todos de finales del siglo, o incluso de comienzos del XIX, como el de la parroquia de Santiago, marcado por el platero ecijano Colmenares, o el de la parroquia de Santa Bárbara, con marca cordobesa. De finales del primer tercio del siglo XVIII es el de parroquia de San Juan, con marca madrileña, todos en Écija. Pero quizá el ejemplo más interesante sea el ya mencionado del convento de la Encarnación de Osuna, en el que sobre la caja eucarística, de perfiles curvilíneos y decoración de grandes cartelas de rocalla en sus caras, se coloca el grupo escultórico del pelícano con sus crías $^{22}$.

Siguiendo con la función eucarística, hay que dedicar especial atención a los cálices, que dada su abundancia, nos permiten seguir perfectamente la evolución del estilo. Los cálices son las piezas más representativas y abundantes de la orfebrería religiosa, más incluso que los copones y custodias portátiles u ostensorios, y su variada tipología nos permite observar todos los pasos de su evolución. Y va a ser en estas piezas en las que se podrá seguir rigurosamente el cambio de estilo del Barroco al Rococó, ocurrido a mediados del siglo XVIII.

En la primera mitad de este siglo tenemos ejemplos claros, completamente cubiertos de hojarasca, compuesta por flores carnosas y hojas, elementos propios de la ornamentación barroca, que hallamos repartidos por todos los templos de las ciudades mencionadas.

${ }^{21}$ ORTIZ JUÁREZ, Dionisio: "Una destacada obra de platería cordobesa en la catedral de Caracas", Boletín de la Academia de Córdoba, 1980, pp. 396-404.

${ }^{22}$ SANZ, María Jesús: "La orfebrería en el monasterio ...", op. cit., pp.110, fig. 9. 
En la segunda mitad del siglo, con el cambio de estilo, los elementos decorativos mencionados desaparecerán para ser sustituidos por la rocalla, que en sus distintas formas ocupará todas las superficies posibles, y ocultará la estructura de las piezas. Entre los ejemplares más destacados podemos citar el de la catedral de Sevilla, obra de Damián de Castro, en oro, cabeza de toda una serie, en las que el nudo calado aloja algún elemento eucarístico. Son destacables también los magníficos relieves del basamento (figura 5). Algunos años después, repitió el modelo en Priego (Córdoba), aunque realizado en plata. Más tardío aún es el del santuario de Consolación de Utrera, o bien el de la iglesia del Carmen de Estepa, que muestra una cierta influencia cortesana por la estilización de su astil (figura 5b).

El estilo plenamente rococó tiene otros bellísimos y originales ejemplos en Écija, obras de Damián de Castro, como el de la parroquia de Santa Cruz, que si lo comparamos con uno propiamente barroco veremos cómo se ha trasformado, no sólo en la decoración sino también en la estructura.

Este diseño de movido perfil aparece también en casi todas sus obras, y especialmente en las superficies planas que convierte en unas bellas placas decoradas, como por ejemplo en los portapaces, que de estar diseñados como pequeños retablitos durante los estilos anteriores ahora se convierten en placas de recortados perfiles, como podemos ver en el portapaz de la parroquia de Santa Cruz, de Écija (figura 6). Si lo comparamos con cualquiera de los varios portapaces barrocos que se conservan, como por ejemplo el de la parroquia de Santa María de Carmona (figura 6b), estructurado como un auténtico retablito barroco con sus tres calles enmarcadas por cuatro columnas salomónicas, y con la imagen de la Inmaculada en la calle central ${ }^{23}$, veremos la gran trasformación efectuada.

El mismo aspecto de superficies completamente decoradas presentan las lámparas de plato de estilo rococó entre las que podría destacarse una de las existentes en Écija, como la de iglesia del Carmen, fechada en 1775, obra asimismo de Castro, que muestra como originalidad un perfil triangular, cuando lo habitual es que sea circular.

Otro de los campos donde la orfebrería barroca y rococó ha producido más obras ha sido en el exorno de las imágenes, tanto en las piezas para la capilla, como en las de procesión. Coronas, ráfagas, medias lunas, puñales, etc. Se hacen de plata para embellecer a las imágenes de la Virgen especialmente.

Como modelo de las primeras coronas barrocas puede considerarse una corona de la Virgen de la parroquia de San Pedro de Carmona, pieza fechada en 1640, decorada con la vegetación barroca propia del inicio del estilo, pero presentando aún cabujones de esmalte propios del manierismo (figura7). Pero, desde mediados del siglo XVIII, veremos que la trasformación decorativa alcanza a todas las piezas de plata y por supuesto a la ornamentación de las imágenes. Con

${ }^{23}$ MEJÍAS ÁLVAREZ, María Jesús: Orfebrería religiosa ..., op. cit. pp. 618, 631 y 642. 
todo rigor podemos decir que el más suntuoso conjunto de toda Andalucía es el que luce la Virgen de la Soledad del templo de Nuestra Señora del Carmen de Écija, obra de Damián de Castro, realizado entre 1768 y 1769, que se compone de corona, ráfaga y media luna ${ }^{24}$.

Aunque la corona (figura 7b), la ráfaga y la media luna de la Soledad sean las piezas más suntuosas del rococó andaluz (figura 8), hay que mencionar otras coronas y ráfagas de diseño más tradicional, pero también de gran riqueza, como por ejemplo la ráfaga de la Virgen del Carmen en el convento del mismo nombre de Estepa. La de la Virgen de los Dolores de la Iglesia del Servitas en Osuna, que es una obra cordobesa elegante y equilibrada del más puro barroco, aunque la ráfaga corresponde ya al estilo rococó (figura 8b). Algo más avanzada es la de la Virgen de la Merced, en el mencionado convento de la Encarnación de Osuna, con original diseño de ráfaga de perfil trilobular y rayos que se forman por módulos rosáceos de tres puntas, y que se adornan con piedras verdes.

$\mathrm{Y}$, siguiendo el aspecto procesional, tenemos que mencionar otras piezas fundamentales en el desfile, como las cruces procesionales y las custodias. Estas últimas pueden ser de mano, las más abundantes, utilizadas durante el culto, pero también para la procesión del Corpus, en los casos en que la iglesia de la localidad no disponga de custodias de torre o asiento. Las custodias de mano u ostensorios se hallan en la misma línea estructural que los cálices, aunque en general son de mayor envergadura y permiten una mayor introducción de elementos. Son abundadísimas y a través de ellas puede verse también el cambio de estilo desde el manierismo al barroco y del barroco al rococó. Entre las de estilo rococó podemos destacar alguna realizada en Sevilla para el convento de La Paz de Fregenal, (Badajoz) o la de El Rubio, en plena Campiña, pero sobre todo destacan las de Damián de Castro, repartidas por distintas localidades de toda la provincia de Córdoba, y también fuera de ella, en otras localidades de la Península y de Canarias. Entre ellas, podría destacarse la custodia de la catedral de La Orotava por la originalidad del modelo. La obra presenta un astil ondulante por la introducción de cuatro ensanchamientos que se unen mediante línea continua. El sol se forma por una serie de rayos biselados entre los que intercalan módulos calados con remate de estrellas. Se fecha en 1768.

Entre las obras de mayor envergadura, hay que citar las custodias de torre o de asiento, que habitualmente se construían de plata, siempre que las poblaciones, que no las habían mandado realizar durante los siglos anteriores, dispusieran de los medios adecuados. Cuando las ciudades no disponían de dinero suficiente o de un platero hábil, entonces podían hacerse de madera plateada como en el caso de la de la ciudad de Mairena del Alcor, pero este hecho es muy poco habitual.

${ }^{24}$ GARCÍA LEÓN, Gerardo: El arte..., op. cit., p.235, y El fulgor de la plata, pp. 386387. 
Las custodias de asiento, cuyo modelo creó Enrique de Arfe en la primera mitad del siglo XVI, tuvieron una gran repercusión en todo el territorio español a lo largo de este siglo, constituyendo verdaderos ejemplos de la arquitectura y la iconografía vigentes en el siglo XVI, y siendo casi todos los ejemplares realizados en plata.

Durante los siglos siguientes se siguieron construyendo custodias, verdaderas arquitecturas que se adaptaron al estilo de cada momento. Entre las obras puramente barrocas podemos citar, entre otras, la de la parroquia de la Magdalena de Sevilla, o la de la parroquia de Santa María de la Mesa de Utrera, en la misma línea arquitectónica y escultórica, aunque de distintos autores (figura 9). Ambas presentan las típicas columnas salomónicas, la división en cuerpos decrecientes, una iconografía correspondiente a las devociones del Barroco, y una abigarrada ornamentación vegetal. En cuanto a la custodia de Utrera hay que decir que se realizó a lo largo de varios años pues se empezó a finales del siglo XVII y no se acabó hasta bien entrado el siglo XVIII, y hubo distintos autores que intervinieron en su ejecución. El primero es un platero sevillano llamado Blas Ruíz, que firmó el contrato de la custodia en 1678, pero que no pudo terminar la obra porque murió en 1684. Años más tarde, en 1701, intervino Felipe Ponce, también platero sevillano, que conjuntamente con Diego Holgado, platero de la iglesia utrerana, finalizó la obra en $1708^{25}$. Felipe Ponce era algo más conocido por sus obras en Sevilla que los otros dos autores. Con este mismo apellido hallamos dos plateros examinados en Sevilla de maestros, uno es Manuel José Ponce, examinado de maestro platero en 1722, y ya en la segunda mitad del siglo XVIII, en una obra claramente rococó, como es la puerta del sagrario de la parroquia de Santa Catalina de Sevilla, hallamos la marca de Pedro Ponce, ambos sin duda miembros de la misma familia ${ }^{26}$.

Muy diferente es la custodia de la iglesia de San Pedro en Carmona, obra documentada de la primera mitad del siglo XVIII, pero que en realidad reproduce el modelo que Francisco de Alfaro hizo para la parroquia de Santa María de la misma población, en $1584^{27}$. Hecho que resulta sorprendente, reproducir en el siglo XVIII una obra del último tercio del siglo XVI, que sólo resulta explicable por gran influencia de la obra de Alfaro en la ciudad.

Muy interesante es la custodia de la parroquia de Santa María en Fuentes de Andalucía (figura 10). Aunque no es de gran tamaño, y su estructura es de un sencillo templete, muestra los dos estilos a los que nos estamos refiriendo, así como el intercambio de obras y estilos entre Córdoba y Sevilla. El templete, barroco,

${ }^{25}$ QUILES, Fernando: "La custodia de la parroquia de Santa María de la Mesa de Utrera”, Archivo Hispalense, n²22, Sevilla 1990, pp.155-171, Utrera, un enclave artístico en la Sevilla de 1650 a 1750, Sevilla, 1999.

${ }^{26}$ SANZ, María Jesús: Orfebrería sevillana..., op. cit., tomo II, pp. 29 y 64.

${ }^{27}$ GARCÍA LEÓN, Gerardo: El arte de la platería ..., op.cit., pp. 230-233, y 368. 
muestra la marca de un platero cordobés, Vargas, y la fecha de 1751. La peana, de estilo claramente rococó, está marcada por un platero ecijano bien conocido: Franco $^{28}$.

En cuanto a las custodias de estilo rococó, se han perdido algunas de las más representativas, como la ya mencionada de Morón, durante la Guerra Civil, realizada por José Alexandre Ezquerra en 1764, conocido platero sevillano (figura 10b). Como obra cordobesa también perdida puede citarse la que Damián de Castro realizó una para la catedral de Sigüenza, entre 1774 y 1779, desaparecida durante la invasión francesa. Aunque la obra no estaba en Andalucía, se realizó en Córdoba, y evidentemente estaba en la línea de este magnífico platero que tanta influencia tuvo en el rococó sevillano.

En la actualidad, la riqueza de materiales se muestra especialmente en las cruces de guía de las hermandades de penitencia. En la época del Barroco se produjeron ricos ejemplares de cruces, que se presentaron cubiertos de ornamentación vegetal, algunos desaparecidos como la cruz de San Miguel de Morón. Otros, posteriores, correspondientes al estilo rococó, se conservan en abundancia, como la cruz de Damián de Castro en Écija. Y, finalmente, hay que mencionar las cruces de altar, entre las que destacaríamos la de la Encarnación de Osuna, ejemplo en el que el Barroco y Rococó se mezclan, produciendo una imagen de abigarrada decoración.

Otras de las piezas verdaderamente ricas son las cruces de los Nazarenos, generalmente de madera, con aristas y remates de plata, o enteramente recubiertas de plata, como la de la parroquia de San Sebastián de Estepa. En este período las cruces se enriquecen notablemente, utilizando, además de las recubiertas de plata, las que se recubren de carey, o bien las que se adornan con incrustaciones, bien sean de plata, de carey, de marfil o de nácar, como las pertenecientes a la cofradía de los Nazarenos de Utrera, la Hermandad de las Penas en Sevilla, procedente de Écija, o la cruz de la parroquia de San Bartolomé de Carmona, además de otras muchas repartidas por toda Andalucía. Casi todas ellas están realizadas entre los últimos años del siglo XVII y la primera mitad del XVIII, con carey procedente de América. El trabajo del carey y de plata es debido a ebanistas y plateros andaluces ${ }^{29}$.

En cuanto a la ciudad de Osuna, su patrimonio artístico muestra algunas diferencias con el resto de las poblaciones de la Campiña, debido, como ya hemos mencionado, a la dependencia de la ciudad de los Duques de Osuna, que tuvieron importantes cargos en Italia, además de propiedades en otros lugares de España,

${ }^{28}$ MORALES, Alfredo, SANZ, María Jesús, SERRERA, Juan Miguel y VALDIVIESO, Enrique: Guía artística..., op. cit., tomo II, p. 229.

${ }^{29}$ SANZ, María Jesús: "Cruces ricas de nazarenos andaluces”, IX Simposio sobre hermandades de Sevilla y su provincia, Sevilla, 2008, pp. 195-221. 
y por ello existen piezas procedentes de Madrid $^{30}$, Valladolid e Italia. No obstante, no hay un estudio de toda la platería religiosa de Osuna, como los hay de otras poblaciones. Entre las colecciones estudiadas están, además de la de la Colegiata, la de la parroquia de Nuestra Señora de Consolación y la del monasterio de la Encarnación, en las que existen piezas de estilo barroco y rococó. Entre las piezas de estilo rococó habría que citar la cruz de altar de Juan Nicolás Bravo, del Monasterio de la Encarnación ${ }^{31}$, obra ya mencionada, y muy interesante, en las que las rocallas muestran un gran movimiento en la peana, y la cruz presenta unas cresterías en las que intervienen las rocallas y la convierten en una obra de gran riqueza. La marca de Juan Brabo aparece en distintos lugares de la obra. En el mismo monasterio se halla un San Miguel Niño adornado con casco, espada, escudo, balanza, y así mismo un Niño Jesús de la Pasión, que lleva unos zapatitos marcados por Rodríguez ${ }^{32}$, todo realizado en la más delicada rocalla.

No podemos terminar de tratar este período sin mencionar las piezas extranjeras, que, como ya advertimos, existen algunos ejemplares en Osuna. La más colorista es, sin duda, la custodia adornada con esmaltes blancos y coral del convento de La Encarnación, obra siciliana de finales del siglo XVII, relacionada evidentemente con el gobierno de los Osuna en Nápoles. La Colegiata posee también un conjunto italiano, de jaspe y metal, procedente también del sur de Italia. Se trata de dos candeleros de altar, unas vinajeras con su bandeja y un portapaz, en el que se representa la figura del Ecce Homo. Todo el conjunto fue regalado en 1612 , y realmente no se pueden considerar como obras barrocas, sino manieristas, aunque esta donación nada tiene que ver con las piezas que se realizaban en España en estas fechas, ni por el estilo ni por los materiales empleados ${ }^{33}$.

Queda así planteado el panorama del arte de la plata labrada en la Campiña Sevillana y la creación de su patrimonio barroco y rococó, formado por las influencias de las dos grandes escuelas en el arte de labrar la plata, la cordobesa y la sevillana. Aunque algunas localidades poseen piezas procedentes de otros lugares más lejanos, tanto españoles como europeos o americanos, sin embargo el núcleo fundamental de su patrimonio, que es muy abundante, se formará desde estas dos grandes escuelas mencionadas. De la unión de estas dos escuelas, surgirán talleres locales de gran relieve, con una riqueza tanto decorativa como estructural, como

${ }^{30}$ SANZ, María Jesús: "Piezas inéditas del platero Juan de Orea”, Iberjoya, n 20, Madrid, 1980, pp.47-50..

${ }^{31}$ SANZ, María Jesús: "La orfebrería en el Monasterio...” op. cit., SANTOS MÁRQUEZ, Antonio J.: "La orfebrería en la parroquia de Nuestra Señora de Consolación de Osuna", Archivo Hispalense, $n^{\circ} 258$, Sevilla, 2002, pp. 175-185, "Una aproximación al arte de la platería en Osuna”, op. cit., pp. 560-562,

${ }^{32}$ SANZ, María Jesús: "La orfebrería en el monasterio ...”, op. cit., pp. 105-116.

${ }_{33}$ SANZ, María Jesús: Catálogo de orfebrería de la Colegiata..., op. cit., pp. 18-19, $32-33$ y $38-40$. 
en el caso de Écija, cuyo desarrollo, especialmente durante el rococó, sobrepasará al de las dos grandes urbes.

Fecha de recepción: 10 de septiembre de 2014

Fecha de aceptación: 28 de noviembre de 2014

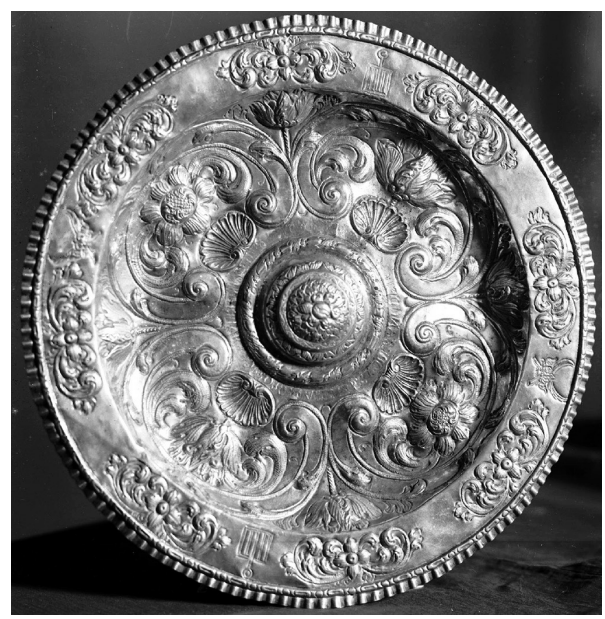

Figura 1a. Fuente de la parroquia de San Lorenzo, Sevilla.

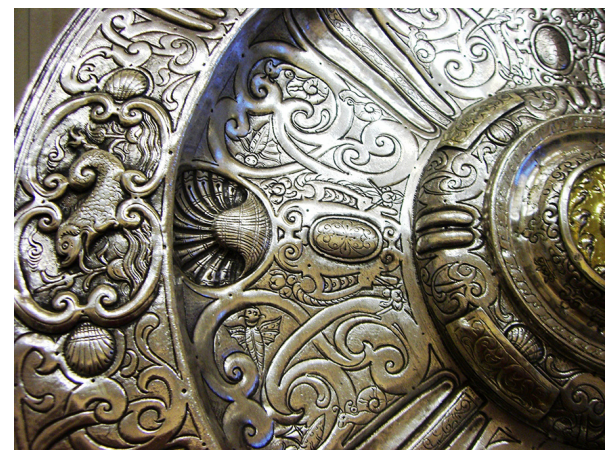

Figura 1b. Fuente de la parroquia de Santa Cruz, Écija. 


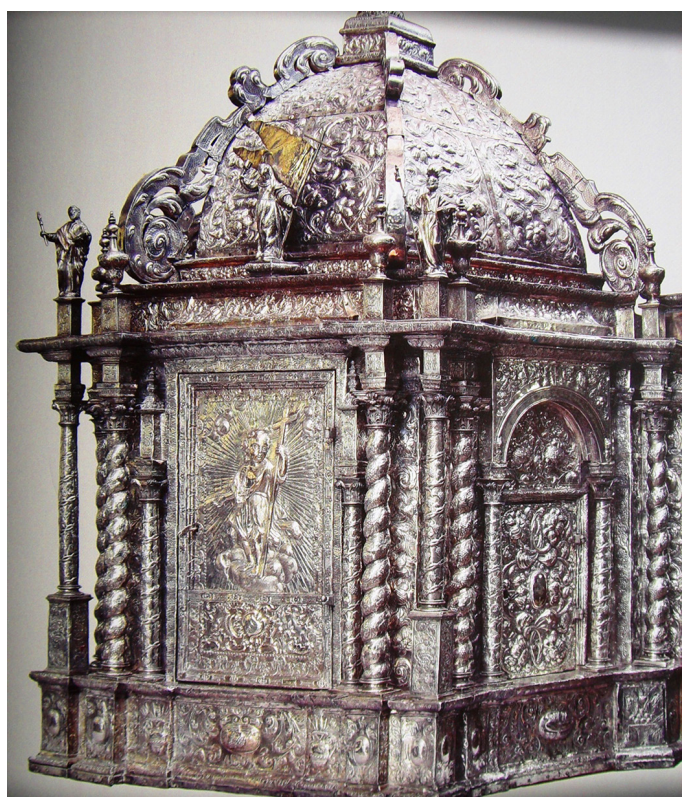

Figura 2. Sagrario de la parroquia de San Miguel, Morón.

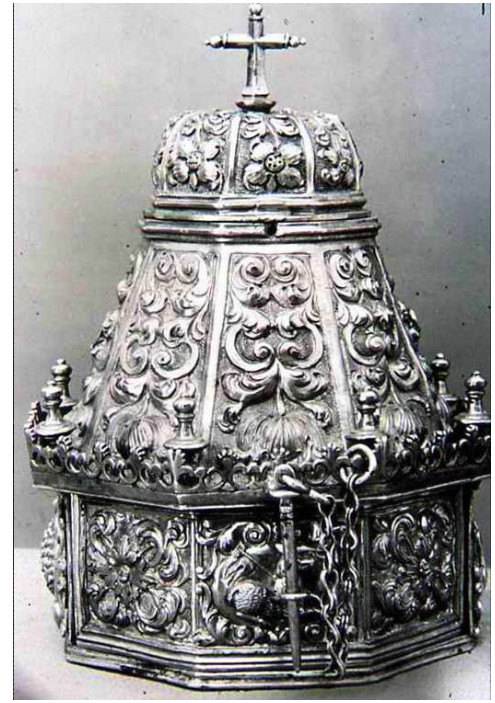

Figura 3a. Urna eucarística de la parroquia de San Miguel, Marchena.

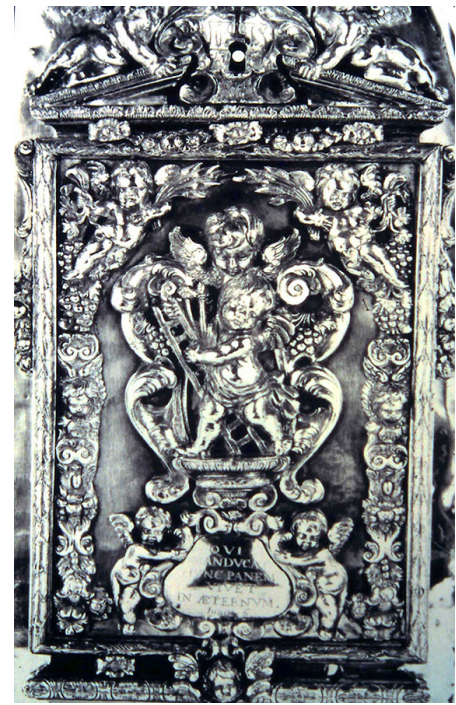

Figura 3b. Paneles de la custodia de la parroquia de San Juan, Marchena. 


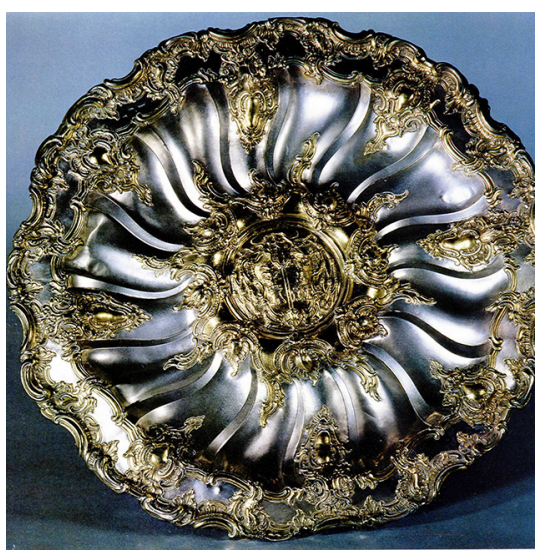

Figura 4a. Fuente de Damián de Castro de la catedral de Sevilla.

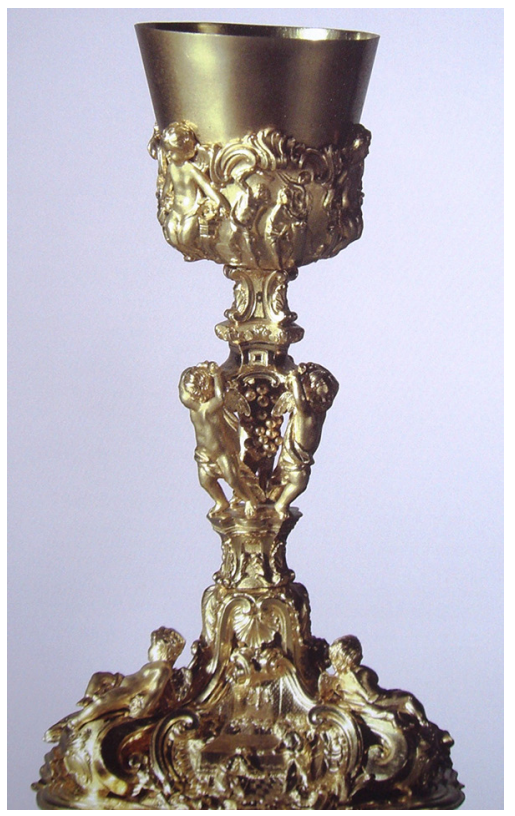

Figura 5a. Cáliz de Damián de Castro, Catedral de Sevilla.

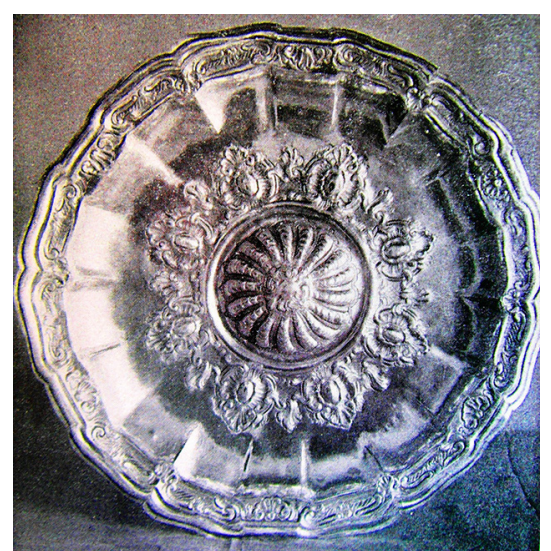

Figura $4 b$. Fuente de la parroquia de Santa María, Estepa.

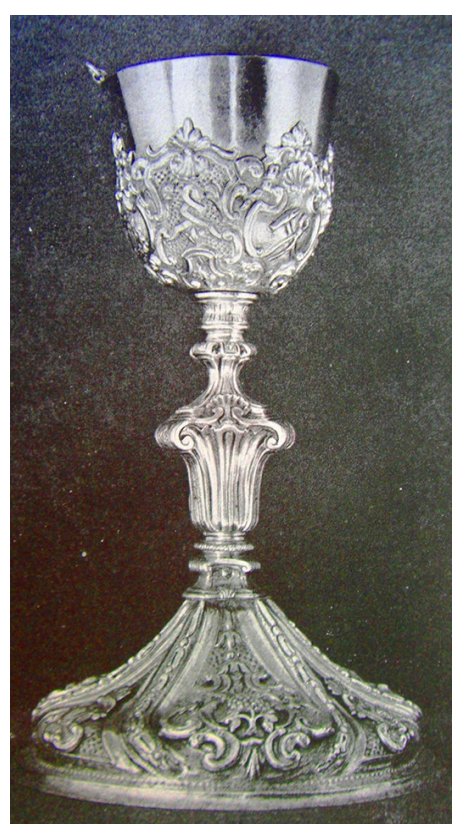

Figura 5b. Cáliz del convento del Carmen, Estepa. 


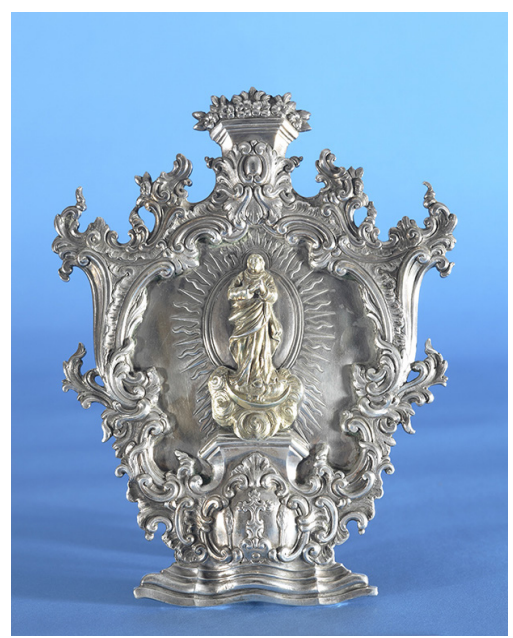

Figura 6a. Portapaz de Damián de Castro, Écija.

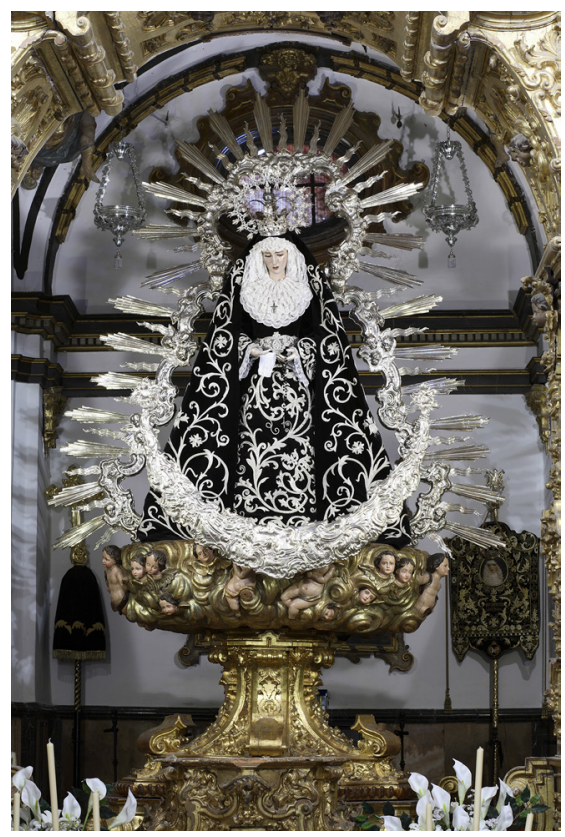

Figura 7a. Imagen de Nuestra de la Soledad, convento de los Descalzos, Écija.

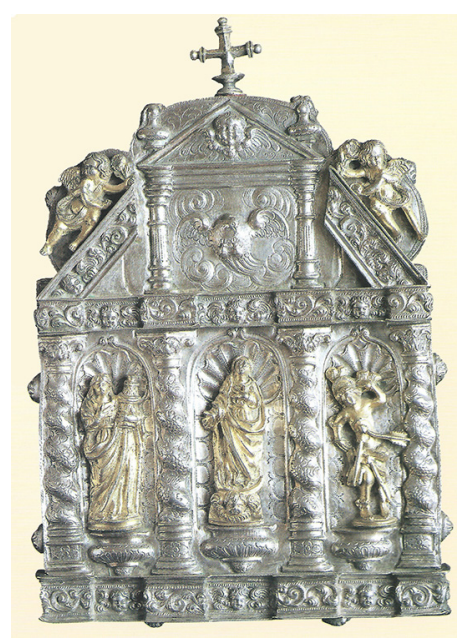

Figura 6b. Portapaz de la parroquia de Santa María, Carmona.

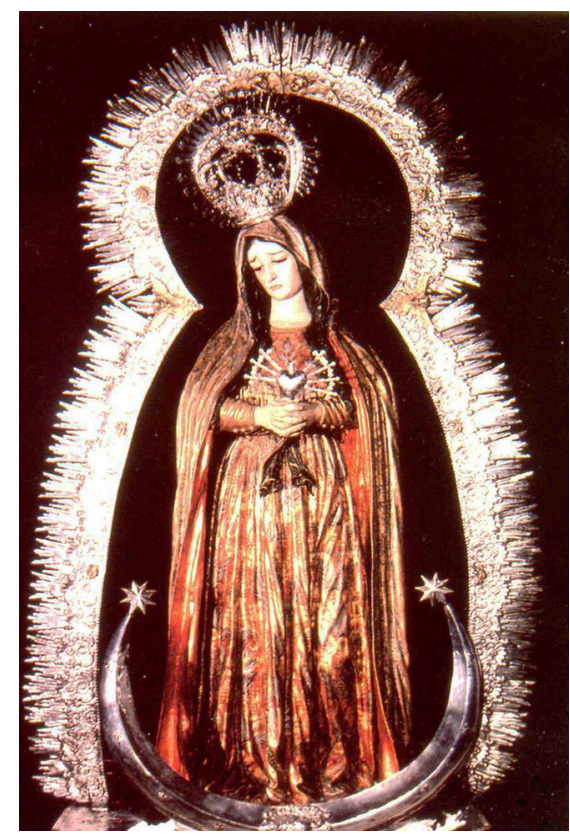

Figura 7b. Imagen de Nuestra Señora de los Dolores, iglesia de los Servitas, Osuna. 


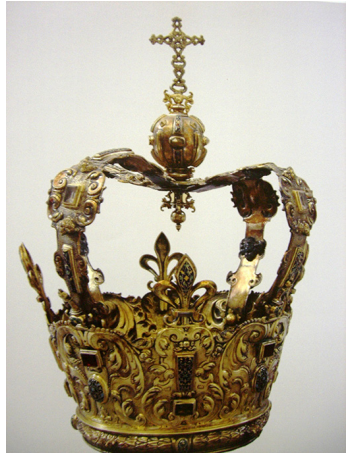

Figura 8a. Corona de la parroquia de San Pedro, Carmona.

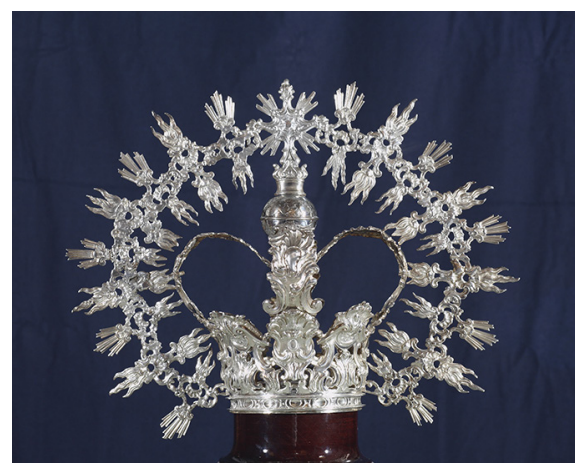

Figura 8b. Corona de la Virgen de la Soledad, del convento de El Carmen, Écija.

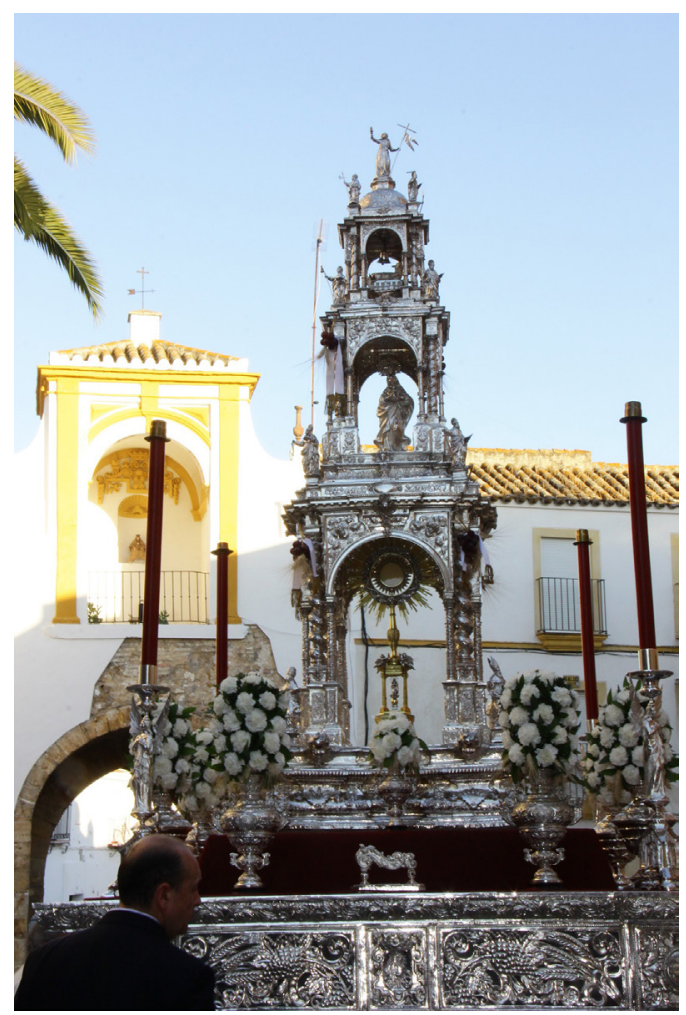

Figura 9. Custodia de la parroquia de Santa María de la Mesa, Utrera. 


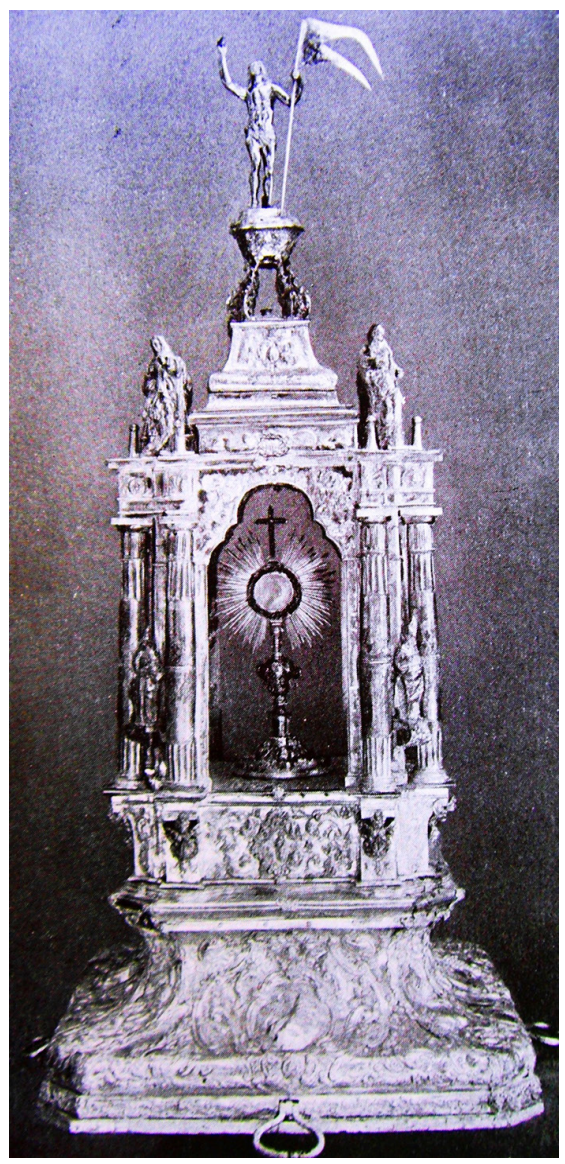

Figura 10a. Custodia de la parroquia de Santa María, Fuentes de Andalucía.

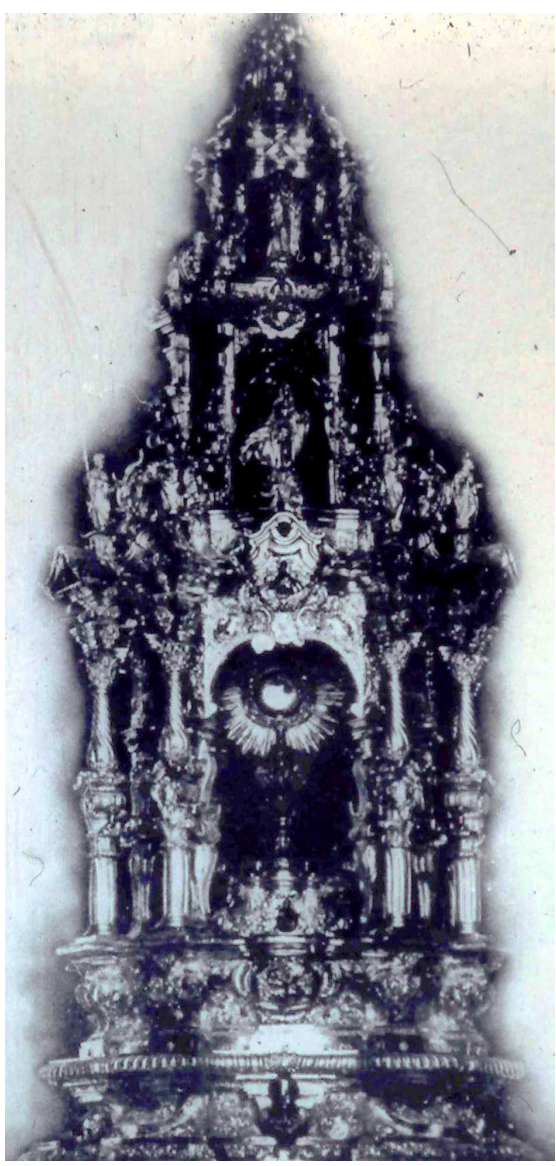

Figura 10b. Custodia de la parroquia de San Miguel, Morón, (desaparecida). 